\title{
Application of Project Management to Materials Selection for Diversified Product Design Parameters
}

\author{
M.-Y. Kang and H.-T. Young \\ Department of Mechanical Engineering, National Taiwan University, Taipei, Taiwan
}

The selection of suitable material is a key step in the product design process. In an increasingly competitive marketplace, not only technology-oriented engineering requirements, but also production-oriented manufacturing and customer-oriented marketing must be included in the analysis of the materials requirements. This work presents a methodology for deriving diversified product design parameters which are function-based and project-oriented for supporting the analysis of materials requirements. When developing the product design parameters, cross-functional problems attributed to the conflicts between functional departments should be resolved by the projectmanagement using a heavyweight team structure in the organisation. The proposed diversified product design parameters form the basis of materials selection rationalisation.

Keywords: Function-based; Project-management; Projectoriented

\section{Introduction}

In the past, materials selection was considered to be a minor part of the product design process. The selection task was based mostly on past experience. Materials were selected from handbooks with a limited choice and on the basis of limited property data. Today, this is an unacceptable approach for the product design process. An improperly chosen material can lead not only to failure of the part or component, but also to unnecessary cost. In many manufacturing operations, the cost of materials may amount to more than $50 \%$ of the total cost. Generally speaking, the steps in the process of material selection can be defined as follows [1]:

1. Analysis of the materials requirements. Determine the conditions of service and environment that the product must withstand. Translate them into critical material properties.

Correspondence and offprint requests to: Dr Ming-Yuan Kang, 13-F-No. 83 Section 2, Cheng-Kung Road, Taipei Country, Taiwan. E-mail: d3502014@ms.cc.ntu.edu.tw
2. Screening of the candidate materials. Compare the required properties with a large material property database to select a few materials that look promising for the application.

3. Selection of the candidate materials. Analyse candidate materials to select the best material for the application.

4. Development of design data. Determine the key material properties of the selected material to obtain reliable measures of the material performance.

It is important to consider all possible alternatives during the design process, since design decisions will play an important role in determining the feasible manufacturing processes and the final product cost. Methodology [2] has been developed for incorporating environmental considerations in the selection of materials at the design phase. A procedure [3] for materials selection is proposed on the basis of integrating it with the manufacturing process. A rational algebra capable of supporting imprecise queries on the database has been developed.

In recent years, the technology of neural networks has been applied to the screening and selection of the candidate materials. Neural networks [4] which have learned pattern sets deal with the interaction between the function of products and materials. In addition, an expert system approach $[5,6]$ has been used for supporting the selection of materials and developing design data. An expert system [7] has been used for validating the output of the neural networks and taking care of situations where the neural networks cannot provide a unique solution. An expert system can also provide an explanation for the decisions made by the neural network.

In the literature survey, there is little relating to the development of material properties for materials selection. Development of material properties on a purely rational basis is far from easy. The problem is not only often made difficult by insufficient or inaccurate property data, but is typically a decision-making problem with multiple constraints and without a clear objective. Therefore, it is crucial to develop the methodology for the materials properties on a rational basis.

For materials selection in the product design process, this work proposes "diversified" product design parameters for supporting the analysis of materials requirements. The proposed design parameters which integrate the design objectives of the relevant functional departments are developed in terms of 
design areas [1] - performance, time, cost, and risk. The material properties will be developed on a rational basis by applying the diversified product design parameters in the analysis of materials requirements.

\section{Literature Review of the Organisation for Project Management}

In the last decade, the concept and technology of concurrent engineering [8] has been extensively applied in the product development process. Complicated cross-functional problems arise, which can be attributed to communication and coordination problems between each functional department. Projectoriented project management has been applied in product development within an organisation structure. Figure 1 shows various organisational structures for project management described in published literature [9]. These can be summarised as:

Functional team structure.

Lightweight team structure.

Autonomous team structure.

Heavyweight team structure.

A functional team structure is the most common structure in the product development process. The functional manager (FM) of each functional department is responsible for the business of that particular department. Complicated cross-functional problems of communication, coordination and decision-making occur in product development as the time requirement becomes more important.

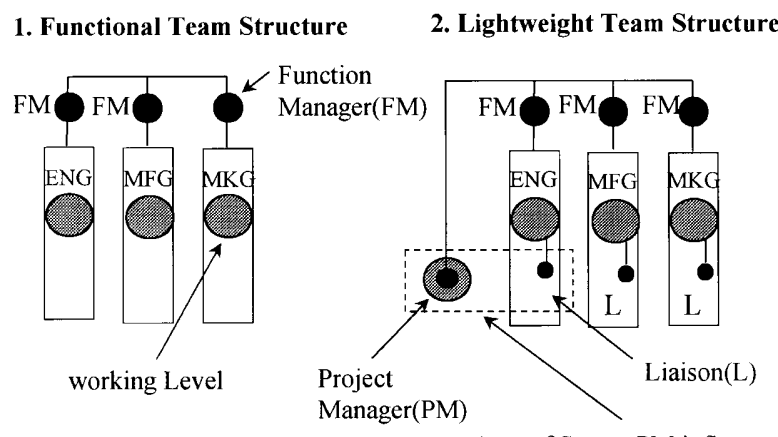

3. Heavyweight Team Structure

4. Autonomous Team Structure

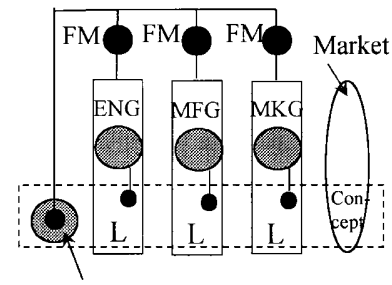

PM

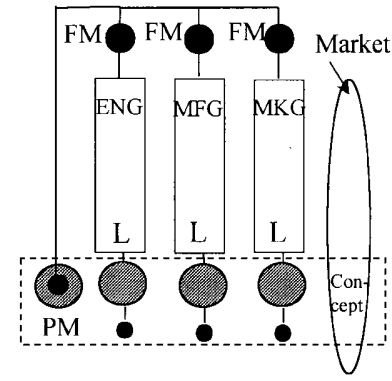

Fig. 1. Team structure of project management.
The solution of the cross-functional problem usually involves the creation of a project-team independent of the functional departments in the organisation. The project-team members come from the related functional departments and represent the perspectives of their departments. A project manager (PM) is responsible for horizontal communication, coordination and decision-making. Recent research involving organisational development has addressed lightweight, autonomous, and heavyweight team structures.

Generally speaking, a lightweight team structure represents a fairly minor modification to the conventional functional team structure. As in the functional structure, those assigned to the team reside physically in their functional areas, but each functional organisation designates a liaison person to represent their functional perspectives on the project coordinating committee. These liaison representatives work with a lightweight manager, who has the responsibility for coordinating the activities of the different functions. However, the lightweight team structure tends to degenerate when the development processes accelerate because much time is spent on communication activities between teams.

The autonomous team structure is an extreme approach. Under this structure, an organisational unit undertakes product development on its own. The team is given a general sense of direction and a budget, and is then separated from the organisation and allowed to work independently. Although this is feasible for start-up companies and new ventures, this approach implies total dependence on one project team. The relatively closed structure may have a negative impact on the implementation of an overall company strategy.

In many cases, a heavyweight team structure is the best one to use. In the heavyweight team structure, the project team must be empowered and trusted. Empowerment not only allows the team to decide on implementation level issues, but also provides it with resources for each phase and clear guidelines and targets, but strategic decisions must be made by the management or by a product approval committee. A project charter and a contract book [10] are instruments for helping to solve the cross-functional problems in this team structure. Heavyweight teams offer improved communication, stronger identification with, and commitment to the project, as well as providing a particular emphasis on cross-functional problem solving.

\section{Diversified Product Design Parameters for Materials Selection}

It is normal to take for granted that the design perspectives of each functional department will be taken into account in the analysis of materials requirements for materials selection. However, materials selection which is carried out only by an engineering department, is usually unacceptable in the production phase for most manufacturing industries. Therefore, design iteration is normally required because engineering design has shown little consideration for overall design aspects. This work presents the use of "diversified" product design parameters which integrate the design perspectives of the relevant functional departments. In this way, the integrity of materials 
selection, which is primarily the responsibility of the engineering department, can be achieved.

\subsection{The Structure of Diversified Product Design Parameters}

Generally speaking, conventional product design parameters are statements [11] relating to the time, cost, size, weight, appearance, performance, durability, etc. within which the design must be constrained. To achieve the objective of diversification, this work proposes diversified product design parameters in terms of design areas - performance, time, cost and risk, for materials selection. The definitions of diversified product design parameters for materials selection are represented as follows:

1. Design parameters of performance area. The design parameters in the performance area for materials selection are composed of size, weight, mechanical, physical, chemical, thermal, electrical, nuclear, fabrication properties, etc.

2. Design parameters of time area. The design parameters in the time area for materials selection are composed of purchasing time, manufacturing time, inspection time, etc.

3. Design parameters of cost area. The design parameters in the cost area for materials selection are composed of purchasing cost, manufacturing cost, labour cost, etc.

4. Design parameters of risk area. The design parameters in the risk area for materials selection are composed of new material evaluation, vender availability, copyright, etc.

\subsection{Cross-Functional Problems of Diversified Product Design Parameters}

The objective of the proposed diversified product design parameters is to provide an integrated environment for materials selection in the product design process. As different considerations regarding the design perspectives may arise from each related functional department, the development of product design parameters usually results in conflicts during design integration. If the communication and coordination of different design perspectives is inadequate, it will require design iteration in the production phase. Consequently the product cost will rise and "time to market" will be delayed. Close examination of each diversified product design parameter reveals that complicated cross-functional problems arise in the decision-making process. Therefore, it is crucial to provide an integrated environment for cross-functional problem solving.

\section{Project Management of Diversified Product Design Parameters for Materials Selection}

Diversified product design parameters are proposed herein in the design areas (performance, time, cost, risk) for materials selection. An attempt is made to resolve the complicated cross-functional problems. Such a solution is achieved by incorporating project management with a heavyweight team structure into the management of the diversified product design parameters.

For project management of the diversified product design parameters for materials selection, the procedure is classified into three phases:

1. Organisation phase. The structure of project management with a heavyweight team structure is top-down designed in the organisation. The project is constructed and empowered through a project chart and a contract book.

2. Functionality phase. The functional design perspectives (socalled functionality) for materials selection are analysed in the project. The relationships between the functional departments and subprojects are established through a functionality diagram.

3. Integration phase. The design perspectives of relevant functional departments are bottom-up integrated through crossfunctional integration using the technology of a decision matrix.

The procedure proposed is defined in detail in the following subsections, and in the flowchart shown in Fig. 2.

\subsection{Organisation Phase}

\section{[Step 1] Project Establishment}

Based on the structure of project management with a heavyweight team structure, a project is independent of the original departments within the organisation. According to the different design areas, the organisation carries out subprojects in per-

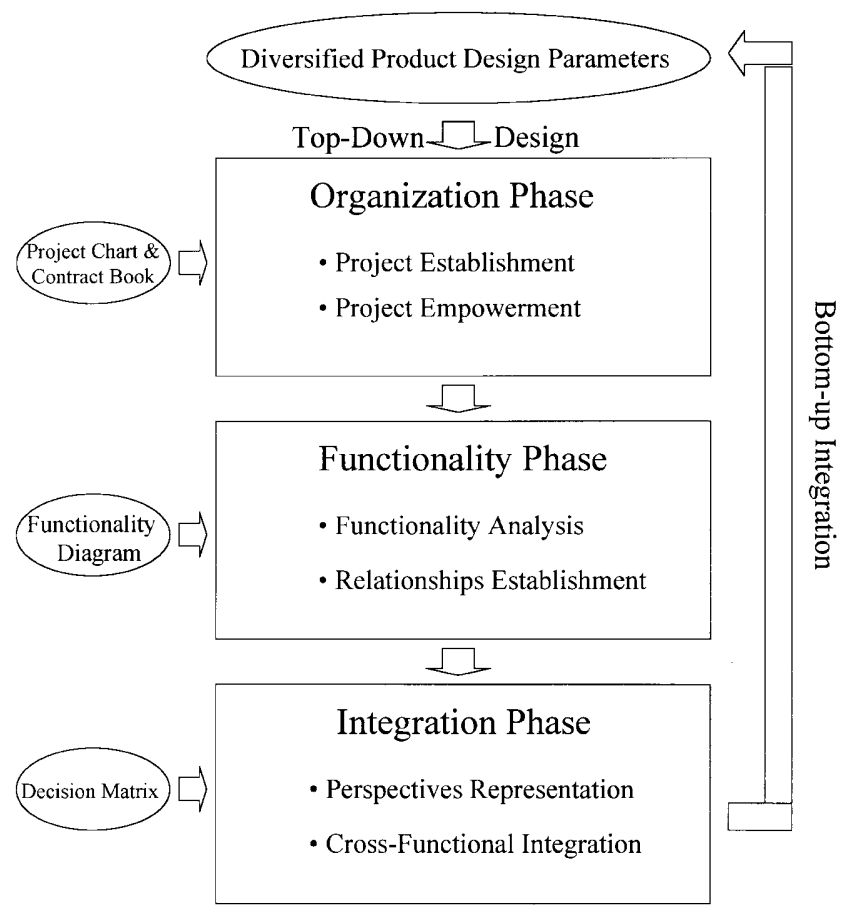

Fig. 2. The flowchart of project management for diversified product design parameters. 
formance, time, cost, and risk. Figure 3 depicts schematically the organisational structure of project management for diversified product design parameters. The elements of the project include a project-team, project-managers, project-team-members, and functional managers. A project charter established by the senior management is introduced to define the objective of the project.

\section{[Step 2] Project Empowerment}

Empowerment implies authorising the project team to determine implementation level issues, as well as providing the team with appropriate resources for each phase and clear guidelines for achieving the targets. The project team requires improved communication, stronger identification with and commitment to the project. A contract book established by the project team is introduced to empower the project.

\subsection{Functionality Phase}

\section{[Step 3] Functionality Analysis}

In order to achieve the objective of diversification, the design perspectives (so-called functionality) from functional departments are analysed in the project for materials selection.

\section{[Step 4] Relationships Establishment}

The relationships between the subprojects (performance, cost, time, risk) and the functional departments are established in the project. A functionality diagram is applied to the definition of the relationships between subprojects and the relevant departments for materials selection.

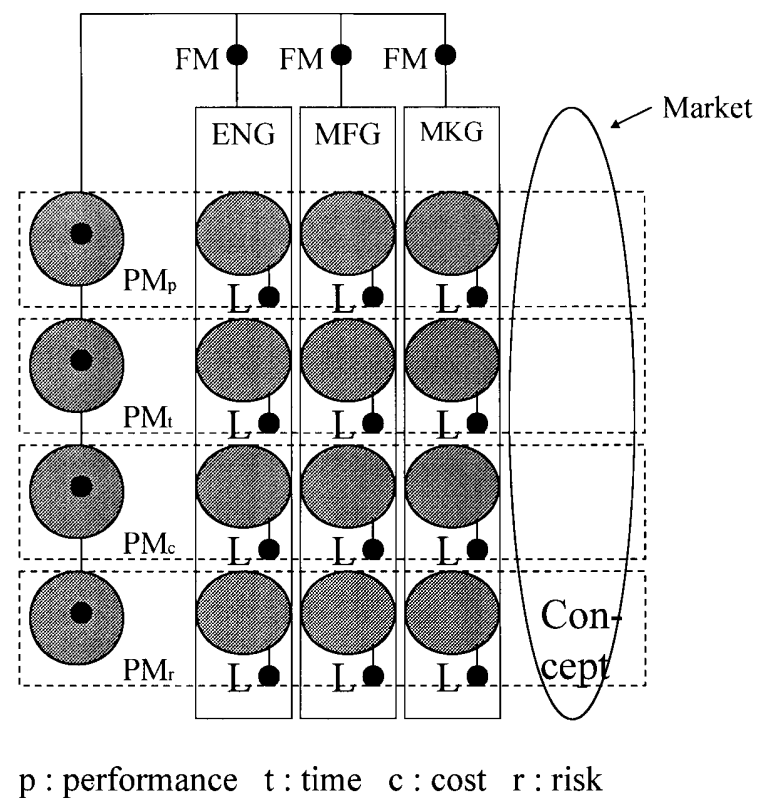

Fig. 3. Project management of diversified product design parameters.

\subsection{Integration Phase}

\section{[Step 5] Perspectives Representation}

The different design perspectives arising from related functional departments are given by original project team members, according to the relationships of the functionality diagram.

\section{[Step 6] Cross-Functional Integration}

Based on the cross-functional problems attributed to the different design perspectives of the relevant departments, crossfunctional integration is carried out using a decision matrix. The diversified product design parameters are bottom-up integrated step-by-step in the cross-functional integration.

In general, the procedure for project management of the diversified product design parameters is proposed in three phases and six steps. Cross-functional problems attributed to the conflicts between relevant functional departments are resolved by the project management with a heavyweight team structure in the organisation. The technologies of the project chart, contract book, functionality diagram and decision matrix are applied by the project management to achieve the objectives of the project. Conflicts arising from top priority domination are controlled by full coordination between the departments, arguments arising from different design perspectives are resolved by improved communication, and misunderstandings are cleared up by strong identification with and commitment to the project. As a result, the proposed diversified product design parameters form the basis of rationalisation for materials selection.

\section{Case Study}

Over $90 \%$ of enterprises in Taiwan industries are small and medium enterprises. Because of the heterogeneous markets, it is important for them to offer high-quality products at lower prices with short delivery times. In order to create competitive advantages, diversified product design parameters are proposed to support the analysis of the materials requirements for rationalised materials selection. The focus of project management with diversified product design parameters may differ in different industries. Manufacturing industry is considered in this work.

The studied company produces internal grinders and $\mathrm{CNC}$ internal grinders in Taiwan. The wheel spindle is the main part of the internal grinder. The wheel spindle [12] is taken as an example to illustrate the project management of the diversified product design parameters for materials selection. The bill-of -materials of the wheel spindle is shown in Fig. 4.

The company's organisation consists of engineering, production-control, material-control, purchasing, manufacturing, quality-control, human-resource and financial functional departments. Every department is supervised by a functional manager. The president and general manager, both having an engineering background, direct this company. 


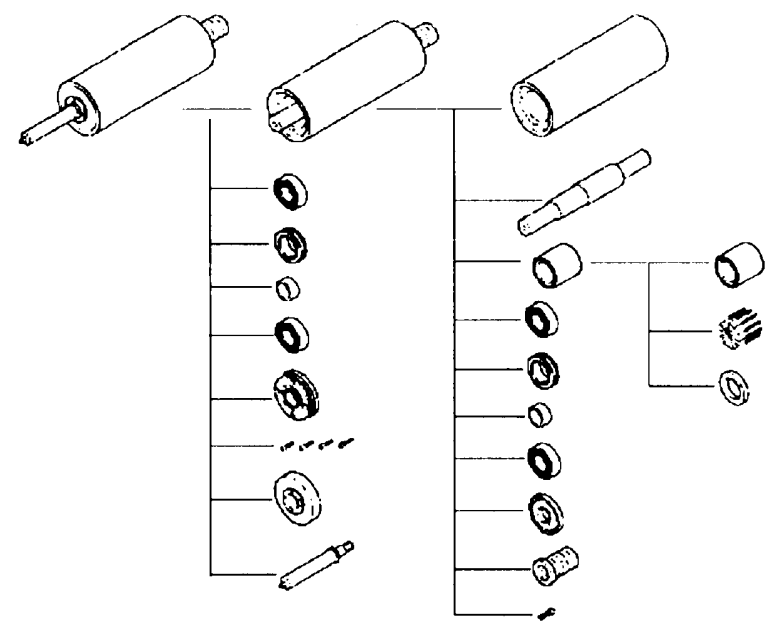

\begin{tabular}{|c|c|c|}
\hline $\mathrm{NO}$ & MATERIA & BOM SODE \\
\hline 3 & Front Screw & $1093 \mathrm{C}-\mathrm{B} 1020$ \\
\hline 12 & Spring & $1093 \mathrm{~L}-\mathrm{B} 3020$ \\
\hline $5,8,14,16$ & Bearing & $1093 \mathrm{~L}-\mathrm{B} 2030$ \\
\hline 20 & Back Screw & $1093 \mathrm{C}-\mathrm{B} 2080$ \\
\hline 4 & Bearing Cover & $1093 \mathrm{C}-\mathrm{P} 1010$ \\
\hline 2 & Front Cover & $1093 \mathrm{~L}-\mathrm{P} 1030$ \\
\hline 1 & Front Spindle & $1093 \mathrm{C}-\mathrm{P} 1040$ \\
\hline 12 & Washer & $1093 \mathrm{~L}-\mathrm{P} 3030$ \\
\hline 7,15 & Oiling Ring & $1093 \mathrm{~L}-\mathrm{P} 2040$ \\
\hline 6,16 & Bush & $1093 \mathrm{~L}-\mathrm{P} 2050$ \\
\hline 18 & Back Cover & $1093 \mathrm{~L}-\mathrm{P} 2060$ \\
\hline 19 & Pulley & $1093 \mathrm{~L}-\mathrm{P} 2070$ \\
\hline 10 & Cover & $1093 \mathrm{~L}-\mathrm{P} 2010$ \\
\hline 9 & Spindle & $1093 \mathrm{~L}-\mathrm{P} 2020$ \\
\hline 11 & Spring Slot & $1093 \mathrm{~L}-\mathrm{P} 3010$ \\
\hline
\end{tabular}

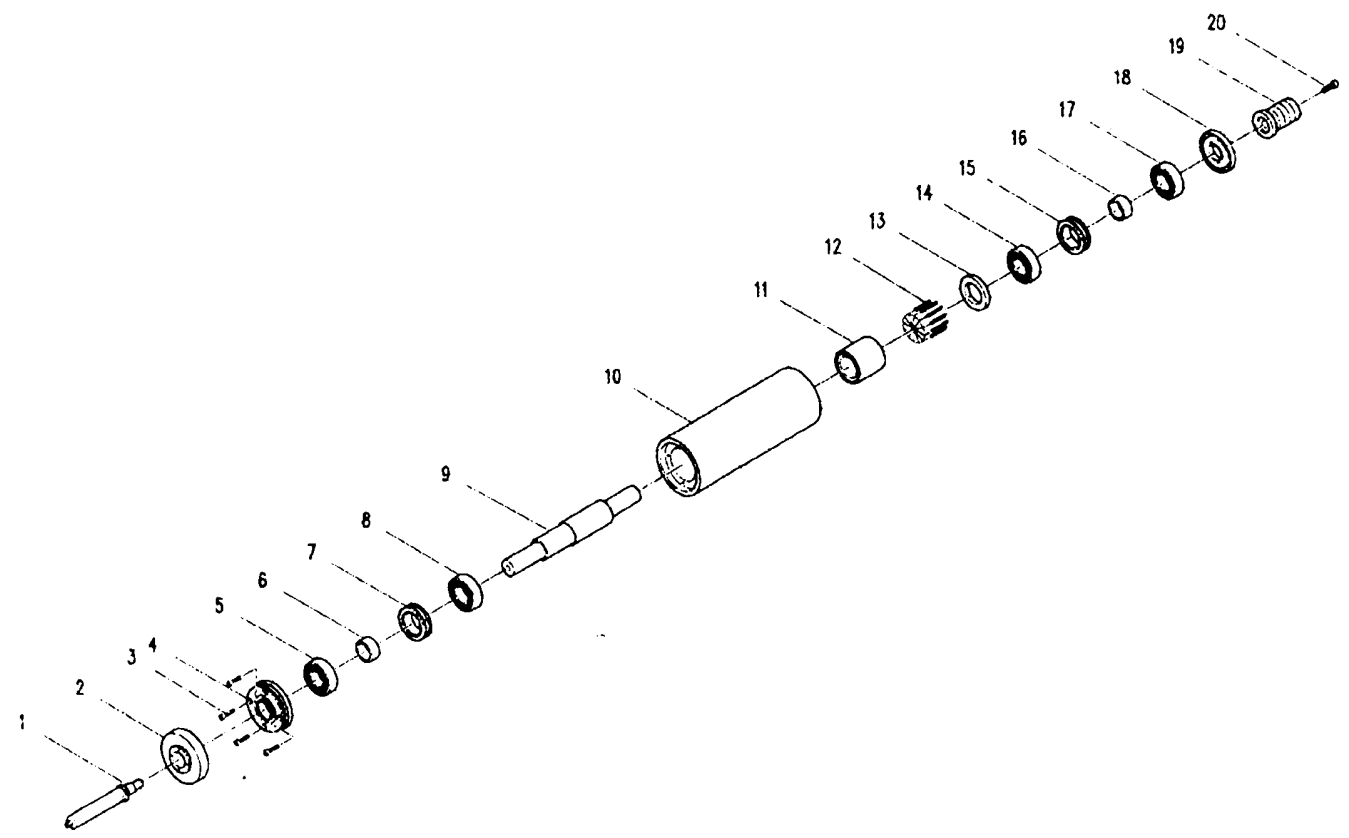

Fig. 4. Bill of materials of wheel spindle for case study.

\subsection{Diversified Product Design Parameters for Materials Selection}

The main attributes for the materials of the wheel spindle can be summarised in seven categories: engineering, purchasing and financial, manufacturing, chemical, physical, quality-control attributes. The definition of the main attributes is shown in Table 1. According to the structure of the diversified product design parameters, the main attributes of materials are divided into four design areas: performance, time, cost, and risk. The diversified product design parameters are shown in Table 2 for materials selection of the wheel spindle.

\subsection{Project Management of Diversified Product Design Parameters}

Based on the procedure for project management of the diversified product design parameters proposed in Section 4, the organisation, functionality and integration phases are established sequentially. Data was collected and summarised from interviews with the company.

\section{Organisation Phase}

[Step 1] Project Establishment. A project is independent of the original functional departments in the organisation. The organisation carries out four subprojects: performance, cost, 
Table 1. The materials attributes of the wheel spindle.

\begin{tabular}{|c|c|}
\hline & Engineering attribute \\
\hline Properties & $\begin{array}{l}\text { Mechanical, fatigue, wear, thermal, } \\
\text { fabrication properties }\end{array}$ \\
\hline Size & Size of materials \\
\hline Weight & Weight of materials \\
\hline \multirow[t]{2}{*}{ S-ratio } & Ratio of length to diameter \\
\hline & Purchasing and financial attribute \\
\hline Cost & Purchasing cost of materials \\
\hline Price & Price of product \\
\hline Purchasing time & Purchasing time of materials \\
\hline Transportation & Traffic problem of materials transportation \\
\hline Law & Copyright \\
\hline \multirow[t]{2}{*}{ Vendor } & Vendor available \\
\hline & Manufacturing attribute \\
\hline Surface & Heat treatment of spray \\
\hline Machining time & Machining time of materials \\
\hline Machining cost & Machining cost of materials \\
\hline Machine & Type of machine \\
\hline Tools & Type of machining tools \\
\hline Fixture & Type of fixture/jig \\
\hline Assembly & Procedure of assembly \\
\hline \multirow[t]{2}{*}{ Assembly time } & Assembly time of materials \\
\hline & Quality-control attribute \\
\hline Inspection item & Inspection item of materials \\
\hline Equipment & Type of inspection equipment \\
\hline Inspection time & Inspection time of materials \\
\hline Inspection cost & Inspection cost of materials \\
\hline \multirow[t]{2}{*}{ Error } & Inspection error \\
\hline & Chemical attribute \\
\hline Poison & Poison of materials \\
\hline Oxidation & Oxidation resistance of materials \\
\hline \multirow[t]{2}{*}{ Corrosion } & Corrosion of materials \\
\hline & Physical attribute \\
\hline Temperature & Thermal stability of materials \\
\hline Conductivity & Conductivity of materials \\
\hline Fire resistance & Fire resistance of materials \\
\hline
\end{tabular}

time, and risk. Staff chosen from the relevant functional departments form the project team members. The project managers chosen from top management and the project team members comprise the project team which is responsible for the development of the diversified product design parameters. As defined by senior management, the project charter expresses a clear mission. Each project team member must, before joining the team, understand fully and follow the guidance of the charter. The project charter is established as follows:

"Diversified product design parameters are proposed for the materials selection of the wheel spindle. Design iteration must be minimised and the project must provide a high-quality product with a lower price in a significantly shorter time."

[Step 2] Project Empowerment. The project-team must understand the mission defined by top management. The team is given time to write a contract book which empowers the project. The general manger of this company was chosen to be project manager and he must ensure that complete
Table 2. The diversified product design parameters for materials selection of the wheel spindle.

\begin{tabular}{ll}
\hline & Performance area \\
Properties & Surface \\
Size & Machine \\
Weight & Tools \\
S-Ratio & Fixture \\
Inspection item & Assembly \\
Equipment & Temperature \\
Error & Conductivity \\
Poison & Fire resistance \\
Oxidation & Corrosion \\
& Time area \\
Purchasing time & Machining time \\
Inspection time & Assembly time \\
& Cost area \\
Purchasing cost & Machining cost \\
Inspection cost & Price \\
& Risk area \\
Vendor & Law \\
Transportation & \\
\hline
\end{tabular}

communication and coordination is carried out between departments. In this case, a contract book is used which specifies:

1. The mission of the project manager is to communicate and coordinate the resources for materials selection.

2. The mission of the project team members is to represent the design perspective of their original departments for materials selection.

3. The mission of the functional manager is to make the project work in the production phase.

\section{Functionality Phase}

[Step 3] Functionality Analysis. Functional design perspectives are analysed between the functional departments for materials selection of the wheel spindle. Functionality of the departments is shown as follows:

1. Engineering: environmental requirements, machining type, machining tools, etc.

2. Production control: resources (tools, manpower) coordination, etc.

3. Material control: inventory control, storage problem, etc.

4. Purchasing: availability, vendor, purchasing policy, etc.

5. Manufacturing: machining technique, machinability, etc.

6. Quality control: inspection tools, inspection technique, etc.

7. Human resource: manpower, direct/indirect duty coordination, etc.

8. Financial: direct/indirect cost, cost control, etc.

[Step 4] Establishment of Relationships. The relationships between the subprojects (performance, time, cost, and risk) and the functional departments are established according to the 


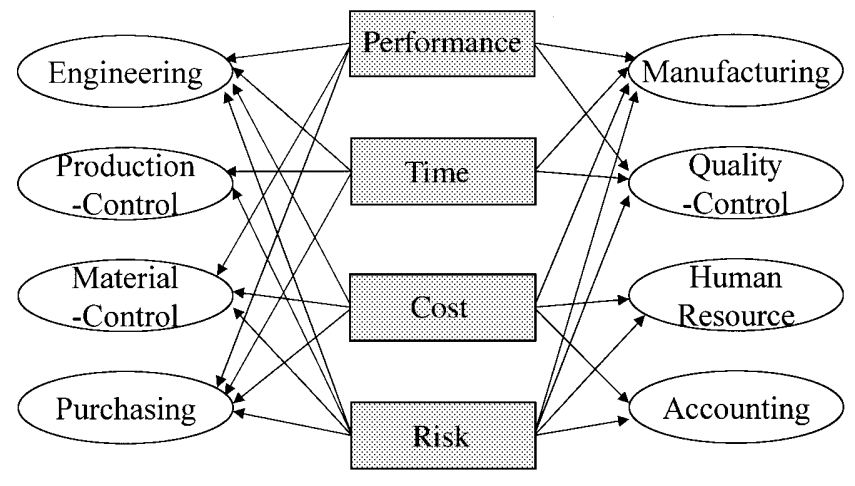

Fig. 5. Functionality diagram for materials selection of wheel spindle.

functionality of the department. Take the performance area of design parameters, for example, the functionality of the relevant departments (i.e. the engineering, material-control, purchasing, manufacturing and quality-control departments) is in connection with the performance area. The relationships are established by way of the interviews carried out for the project. The functionality diagram is established and is shown in Fig. 5. According to the functionality diagram, the working levels of project management are also established and are shown in Fig. 6.

\section{Integration Phase}

[Step 5] Perspectives Representation. Based on the relationships between the functional departments and the subprojects, the project team members represent their different design perspectives in terms of their own functional viewpoints. The performance area of the design parameters is considered as an example. The project team members from the related functional departments present their original design perspectives for materials selection as follows:

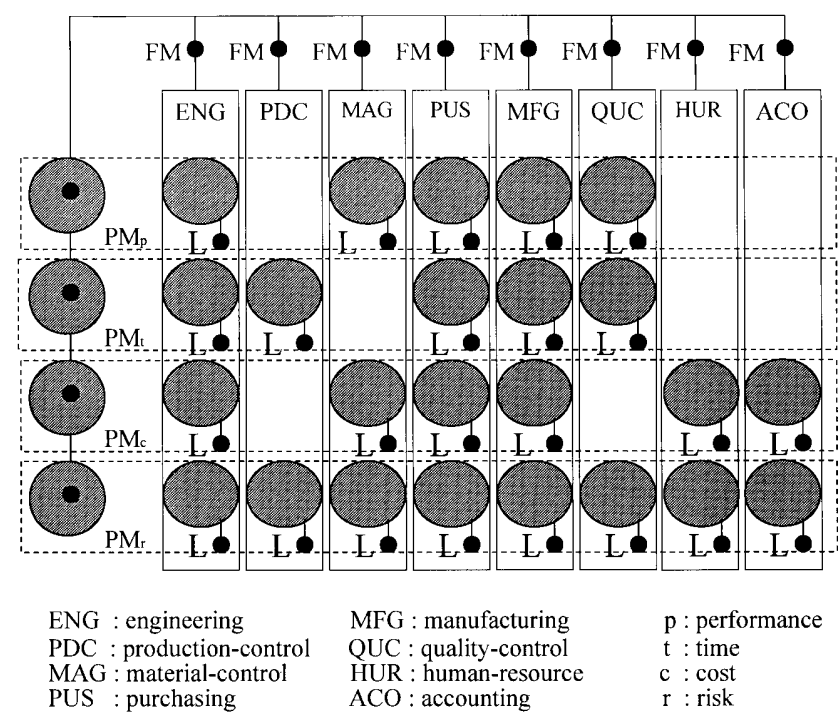

Fig. 6. Project management of diversified product design parameters for case study.

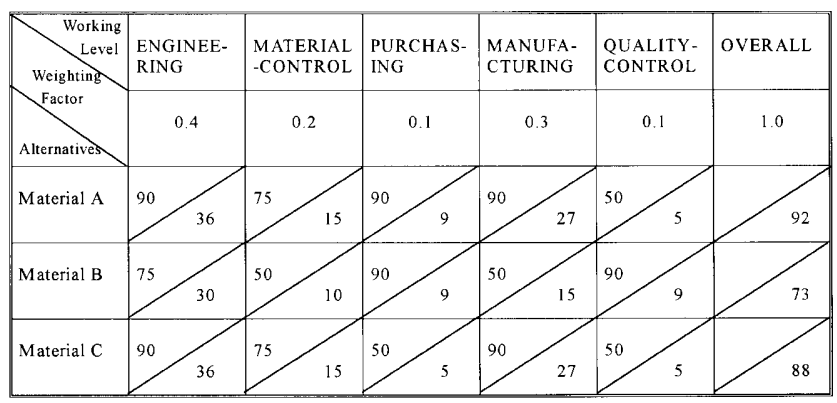

Fig. 7. Decision matrix of the performance design parameters for case study.

1. Engineering considerations of the mechanical properties and production planning.

2. Material-control considerations of inventory and storage.

3. Purchasing considerations of the purchasing policy and transportation problem.

4. Manufacturing considerations of the manufacturing technique and machinability.

5. Quality-control considerations of the measuring technique and measuring procedure.

[Step 6] Cross-Functional Integration. The cross-functional integration of different design perspectives is implemented by using a decision matrix. Take the performance area of the design parameters as an example, a decision matrix for materials selection of the spindle (BOM Code 1093L-P2020) is shown in Fig. 7. Alternatives (materials A, B, C) are proposed by the engineering department. The satisfaction ratings of the decision matrix are established in the project according to Table 3 . The outcomes multiplied by the weighting factor are summed for the functionality for each alternative. In this case, material A having the greatest overall satisfaction is selected. Finally, all design perspectives attributed to the relevant functional departments are discussed and integrated through a decision matrix with the full communication and complete coordination. Each product design parameter is bottom-up integrated in the project step-by-step. It is evident that

Table 3. Satisfaction rating table [1].

\begin{tabular}{ll}
\hline Rating & Description \\
\hline 100 & $\begin{array}{l}\text { Complete satisfaction; objective satisfied in every } \\
\text { respect } \\
\text { Extensive satisfaction; objective satisfied in all } \\
\text { important aspects }\end{array}$ \\
75 & $\begin{array}{l}\text { Considerable satisfaction; objective satisifed in the } \\
\text { majority of aspects } \\
50\end{array}$ \\
$\begin{array}{l}\text { Moderate satisfaction; a middle point between } \\
\text { complete and no satisfaction } \\
\text { Minor satisfaction; objective satisfied in some but } \\
\text { less than half of the aspects } \\
\text { Minimal satisfaction; objective satisfied to a very } \\
\text { small extent } \\
\text { No satisfaction; objective not satisfied in any aspect }\end{array}$ \\
\hline
\end{tabular}


the proposed product design parameters are diversified for materials selection for the wheel spindle.

\subsection{Conclusions of Case Study}

Diversified product design parameters are applied to support the analysis of the materials requirements. Project management with a heavyweight team structure provides an integrated organisation for cross-functional problem solving. The benefits to the company studied when using materials selection for the wheel spindle are as follows:

1. Materials selection for the wheel spindle is more diversified and rationalised in the design phase.

2. Materials selection for the wheel spindle is more accepted and executable in the production phase.

3. "Time to market" and cost of the wheel spindle are decreased resulting from the improvement of design iteration attributed to proper materials selection.

\section{Conclusions}

This work presents diversified product design parameters which are function-based and project-oriented for supporting the analysis of materials requirements. Cross-functional problems attributed to conflicts between the relevant functional departments are resolved in the organisation by the project management with a heavyweight team structure. The different design perspectives of each relevant department are integrated in the project management of the diversified product design parameters. More importantly, the method forms the basis of rationalisation for materials selection.

The features of the present work include the following:

Diversified product design parameters for materials selection.

A procedure of project management for diversified product design parameters.

A case study showing the project management of diversified product design parameters.
Future work should include the following areas:

Project Management with CPM/PERT should be applied for estimation of time/cost parameters.

An expert system based on the diversified product design parameters should be developed as the basis of rationalisation for materials selection.

\section{References}

1. G. E. Dieter, Engineering Design. A Materials and Processing Approach, McGraw-Hill, New York, p. 368, 1986.

2. R. W. Chen, "Systematic methodology of material selection with environmental considerations", IEEE International Symposium on Electronics and the Environment, pp. 252-257, 1994.

3. R. E. Giachetti, "Manufacturing processs and material selection during conceptual design", Industrial Engineering Research Conference Proceedings 47250, pp. 772-777, 1997.

4. M. Takuma, "Study on support system for materials selection in the design process", Nippon Kilai Gallai Ronbunshu, C Hen/Transactions of the Japan Society of Mechanical Engineers, Part C, 60(574), pp. 2184-2190, 1994.

5. L. Block, "Material-process selection methodology: Design for manufacturing and cost using logic programming", Cost Engineering (Morgantown, West Virginia), 33(5), pp. 9-14, 1991.

6. J. Farris, "Design for manufacture: Expert processing sequence selection for early product design", Annals CIRP 41(1), pp. 481484, 1992

7. V. Goel, "Application of expert network for material selection in engineering design", Computers in Industry, 30(2), pp. 87$101,1996$.

8. H. J. Bullinger and J. Warschat (ed.), Concurrent Simultaneous Engineering Systems, Springer, London, pp. 9-24, 1996.

9. S. C. Wheelwright and K. B. Clark, Revolutionizing Product Development. Quantum Leaps in Speed, Efficiency, and Quality, The Free Press, New York, p. 190, 1992

10. M. E. McGrath, M. T. Anthony and A. R. Shapiro, Product Development Success through Product and Cycle Time Excellent, Butterworth Heinemann, Stoneham MA, p. 61, 1992.

11. R. W. Yeomans, A. Choundry and P. J. W. ten Hagen, Design Rules for a CIM System, ESPRIT, North-Holland, p. 22, 1985.

12. Suhua Hsieh and Kou-Cheng Tsai, "Establishing a storage bay assignment decision support method based upon material attributes", Master Paper of Mechanical Engineering Department, Taiwan University, p. 100, 1998. 